\title{
Intratumoral IL-15 potentiates radiation-induced anti-tumor immunity
}

\author{
Karsten Pilones ${ }^{1 *}$, Joseph Aryankalayil ${ }^{2}$, Silvia Formenti ${ }^{3}$, Sandra Demaria ${ }^{4}$ \\ From 30th Annual Meeting and Associated Programs of the Society for Immunotherapy of Cancer \\ (SITC 2015) \\ National Harbor, MD, USA. 4-8 November 2015
}

Radiotherapy (RT) can induce $\mathrm{T}$ cell-mediated anti-tumor immune responses by multiple mechanisms but is often unable to overcome immunosuppression in the tumor microenvironment. The common gamma-chain cytokines interleukin (IL)-2 and IL-15 promote the proliferation of activated $\mathrm{T}$ cells and, therefore, are prime agents for immunotherapy strategies aimed at sustaining anti-tumor $\mathrm{T}$ cell responses. The benefits of high dose IL-2, however, are undermined by serious toxicity and by regulatory $\mathrm{T}$ cell (Treg) stimulation. In contrast, IL-15 is well-tolerated and lacks Treg stimulatory activity, making it an attractive candidate for testing in combination with RT. Here we tested the hypothesis that IL-15 strengthens the pro-immunogenic effect of local RT to potentiate a durable anti-tumor immune response.

The poorly immunogenic mouse TSA breast cancer cells were implanted s.c. in syngeneic BALB/c mice and randomly assigned to one of 4 treatment groups when tumors reached $5 \mathrm{~mm}$ average diameters: control, RT, IL-15 or $\mathrm{RT}+\mathrm{IL}-15$. RT was delivered locally in 8 Gy fractions on days 13,14 and 15 . IL-15 (2 $\mu \mathrm{g} /$ mouse) was administered s.c. peritumorally daily for 10 days starting on day 12 . Mice were followed for tumor growth. A parallel experiment was done to characterize tumor-infiltrating lymphocytes (TILs) at the end of treatment (day 22).

Low dose IL-15 given peritumorally as a monotherapy induced marginal tumor growth control and had no effect on survival (median survival $=45$ days compared to 76 days for control). Local RT significantly delayed tumor growth ( $\mathrm{p}<0.05$ compared to control) and improved survival (median $=76$ days, $\mathrm{p}<0.05)$. However, highest survival advantage was seen in mice given IL-15+RT (median=102 days, $\mathrm{p}<0.05$ compared to all groups) with 1 of 6 mice showing complete tumor rejection and development of anamnestic response against tumor re-challenge. Analysis of TILs showed marked infiltration of CD8 + T cells expressing activation marker CD137 (35.3\% in RT+IL-15 vs $5.9 \%$ in control, $\mathrm{p}<0.05$ ) while the increase was modest with either monotherapy (18.8\% in RT, $20.7 \%$ in IL-15, p < 0.05 compared to control). In addition, we found a significant increase in the ratio of effector CD4+ T cells to Tregs (2.5 in RT+IL-15 versus 0.78 in control, $\mathrm{p}<0.05)$ whereas monotherapy had no effect (1.14 in RT, 0.96 in IL-15).

Overall these results support the rational combination of low dose intratumoral IL-15 with local RT to re-awaken immunity against poorly immunogenic tumors. We are currently elucidating the mechanisms involved in preclinical models in preparation for future testing in patients.

\section{Authors' details}

${ }^{1}$ Weill Cornell Medical College, New York, NY, USA. ${ }^{2}$ NYU School of Medicine, New York, NY, USA. ${ }^{3}$ Weill Cornell Medical College, Radiation Oncology Department, New York, NY, USA. ${ }^{4}$ NYU School of Medicine, Pathology Department, New York, NY, USA.

Published: 4 November 2015

doi:10.1186/2051-1426-3-S2-P239

Cite this article as: Pilones et al: Intratumoral IL-15 potentiates radiation-induced anti-tumor immunity. Journal for ImmunoTherapy of Cancer 2015 3(Suppl 2):P239.

'Weill Cornell Medical College, New York, NY, USA

Full list of author information is available at the end of the article

( 2015 Pilones et al. This is an Open Access article distributed under the terms of the Creative Commons Attribution License (http:// creativecommons.org/licenses/by/4.0), which permits unrestricted use, distribution, and reproduction in any medium, provided the original work is properly cited. The Creative Commons Public Domain Dedication waiver (http://creativecommons.org/publicdomain/ zero/1.0/) applies to the data made available in this article, unless otherwise stated. 